\title{
Sartorial Deconstruction: The Nature of Conceptualism in Postmodernist Japanese Fashion Design
}

\author{
Bonnie English, Griffith University, Queensland, Australia
}

\begin{abstract}
For over 30 years the confrontational work of Yohji Yamamoto and Rei Kawakubo of Comme Des Garcons has challenged traditional tropes and revolutionised the course of the international fashion industry. Within a postmodernist context, fashion as visual arts practice has learned to embrace notions of memory, cognitive association and feminist ideology. Previous conspicuous consumptive patterns succumbed to the new left and crossed boundaries of cultural aestheticism, offering to consumers clothing that was more than merely a "second skin". Yohji Yamamoto's deconstructive style, in particular, articulated the concept of imperfect beauty: dignity masked in the garb of implied poverty; and underlined the role of simplicity and perishability in Japanese aesthetics. At the same time, Rei Kawakubo questioned Western consumers' acceptance of banal fashion that was devoid of intellectual reference or symbolism, by offering clothing that embodied individuality and humanity, closely allied to ambiguous, evocative meaning. This paper will frame Giles Lipovetsky's argument that identity through individualism in dress has become the primary purpose of fashion design in the late 20th and early 21 st centuries. In the trend towards syndication and other globalisation strategies, it will consider how this melding of contemporary cross-cultural influences set a precedent on the catwalks of Paris by embracing the strengths implicit in non-Western traditional cultures. The paper will argue that the impact of the Japanese designers was considerable in terms of changing design directions, construction and finishing techniques, presentation, distribution and marketing. Finally, it will position notions of anti-fashion and the anti-aesthetic in today's society.
\end{abstract}

Keywords: Fashion, Contemporary, Japanese Designers, Yamamoto, Kawakubo, Comme des Garcons, Conceptualism, Deconstruction, Postmodernism, Memory, Meaning, Feminist Ideologies



HEN JAPANESE FASHION designers Yohji Yamamoto and Rei Kawakubo, better known for her Comme des Garcons label, unleashed their fashions on an unsuspecting Parisian audience in 1981, the result was a stunned silence. Never before had such garments graced the French catwalk stage - clothing that resembled spoiled, ripped or torn shrouds, layer over layer of sad-looking black drapes. Grimfaced models were purposely made unattractive with pale pancake make-up, bruised-looking lips and dishevelled hair. It was a visual assault on one of the most heralded events on the Parisian social calendar - who had invited these intruders?

When the international press finally caught their breath, they penned outrageous comments that were to appear on the fashion pages of every major newspaper around the world. Headlines screamed 'Fashion's Pearl Harbour', describing Kawakubo as a 'bag-lady', a derogatory term used in New York to describe down-and-out street dwellers who pick clothing out of garbage bins that they later sold as rags. Kawakubo's curt response was that she actually saw the bag-lady as the 'ideal woman' to dress and that a woman who 'earns her own way' was her typical client. While this seemed a shocking retort for a fashion de-

The International Journal of the Humanities

Volume 9, Issue 2, 2011, http://www.Humanities-Journal.com, ISSN 1447-9508 
signer to make, it was an inherent feminist critique which was echoed in many different forms of art and design practice in the 1980s and 1990s.

Yamamoto offered a different explanation - he said that he liked old clothes as they became like friends that you were reluctant to throw away. He gained much pleasure perusing photographs that the German photographer Auguste Sandler had taken of working class society in the inter-war years. These, he said, inspired his work. The photographs depicted hundreds of anonymous figures wearing boilersuits, dungarees, overalls and pea jackets clothes that sharply reflected their lives. According to art historian Lucy Lippard, both photographs and found objects were used by artists to capture a similar moment in time, a trace of both the presence and the absence of human existence. "Photographs are seen both as facts and as ghosts and shadows. They are the imperfect means by which we fill the voids of memory in the modern culture" (1997: 56). Memory clearly plays a major role in Yamamoto's work. In fact, it could be described as exuding an honourable solemnity, an existential sense of 'self' - garments that become one with the person who wears them, subordinated to the force of his/her personality. At the same time, they possessed a timeless quality. Their understated design underlines the notion that culture, conceptualisation and experimentation can be integral to fashion, as it is to art.

The impoverished aesthetic that the two Japanese fashion designers presented to the world became fashion's response to similar deconstructivist anti-art movements that dominated from the 1980s onwards. One might also argue that the economic recession of the early eighties with the subsequent growth in unemployment created a consumerist environment which embraced this 'aesthetic of poverty'. When sales in luxury commodities began to decline, members of the international fashion syndicates and conglomerates banded together to promote increased spending using the concept of 'branding' as a major marketing strategy. It appealed to the ego of the buyers, a silent whisper that suggested it was important to keep up appearances...if nothing else. This commercial line of attack attempted to reinstate past notions of glamour, status and elitism, reinforcing this paradigm of fashion that had become ingrained over the past 80 years.

Despite this, it must be acknowledged that the Japanese designer labels became part of this branding exercise, as cutting-edge design and consumerism were not mutually exclusive. Fashion historians noted that there was a revolution brewing, as consumers began to look for something more in their fashion purchases than superficial styling and prestigious labels. Instead, they were looking for clothing that said something about themselves. The French scholar, Giles Lipovetsky (1994), argues that identity through individualism in dress has become the primary purpose of fashion design in the late $20^{\text {th }}$ and early $21^{\text {st }}$ centuries.

Perhaps this explains why Yamamoto's 'distressed' black clothing seemed particularly appealing to intellectuals, academics, artists, and even the more conservative architects as it symbolised the cult of the individual. It seemed to merge the emotional, the intellectual, and the aesthetic into one. Perhaps it was a fashion for the sensitive new-age men with the disarray of the fabric mimicking the emotional fragility of the wearer or seen as a symbolic fusion of popular culture and radical thinking. The colour black has played a key role throughout his design career and, if one makes the link with the bohemian black dominating

\footnotetext{
${ }^{1}$ This term 'aesthetics of poverty' was coined by Harold Koda, fashion historian at the Metropolitan Museum of Art, New York when he first saw the work of the Japanese designers. He compared the trend to the 1890s, when “decadence was seen as an aesthetic ideal" (Martin \& Coda 1993:97).
} 
the sartorial landscape of the 1950s, it is not surprising that he has been described, a number of times, as an existentialist thinker. Interestingly, Miyanaga explained that "amongst the older (Japanese) generation, Jean-Paul Sartre had been extremely popular in 1950s and 60s... and his philosophy suggested to these Japanese, who felt lost between tradition and westernisation (after WW11), that continuity between the past and the future was an act of social creation, brought about by human efforts" (1991: 10). Many intellectuals, in their writing and their debates attempted to consolidate this synthesis [between the past and the future], based on interpretations of Sartre's thought.

While we appreciate that, in the visual arts, the meaning of the term deconstruction emanated from the influential French style of philosophical thought and the writings of Jacques Derrida; in terms of fashion, it began to gain currency following the Deconstructivist Architecture exhibition held in 1988 at MoMA, New York. In her essay entitled 'Undressing Architecture: Fashion, Gender and Modernity', the architect Mary McLeod (1994: 92) makes a link between the lexicon of concepts such as structure, form, fabrication and construction that both fashion and architecture share. From this point onwards, fashion journalists including Amy Spindler of the New York Times (1993) began to refer to deconstructivist fashion as a means to loosely reference methodological analysis and critique of fashion's unfinished appearances.

For the Japanese, the literal dismantling of a material, a construction technique, or an idea was closely linked to concepts of Zen Buddhist beliefs where beauty is found in objects which are aged with time and use and where individuality or difference appealed to the humanistic spirit. That which is omitted, whether in literary writing or the visual arts, creates an ambiguity which, in turn, becomes a 'suggestion' of meaning that is the source of its beauty. The Japanese concept of imperfect beauty could be interpreted as dignity masked in the garb of implied poverty, or a fragile perishability.

In terms of Japanese deconstruction clothing design, techniques were deliberately compromised: hems were scissor-cut and uneven; fabric was knotted; deliberate holes or dropped stitches appeared in knitting; threads used for seaming were of an opposite colour and they took on the effect of broad basting, normally used in the preliminary stages of construction. Pattern-making moved away from the modernist tropes of standardisation and modularisation, and form became divorced from function. While only the finest fabrics were used, haute couture techniques were sabotaged; traditions of fine finishing broken; and spatial concepts re-positioned themselves in relation to the body underneath.

Fashion journalists loved to attend the Comme des Garcons collection showings as one learned to 'suspect the unsuspected' in Kawakubo's work. Called 'Dress Becomes Body' 1997 but re-named the 'Bump' collection by the press, she attempted to deconstruct the human figure as well as the garment. Implicit in the message was the feminist sentiment that 'women should be admired for their minds and not their bodies', a response commonly used by Kawakubo. De-construction not only applied to the making of the garment but to the selling and promoting of the product as well. Kawakubo had worked on a collaborative photographic project with the fine artist, Cindy Sherman, a few years earlier (1994) as a means of publicising her collection in a different postmodernist format. While Sherman chose the Comme clothing that she wished to wear, it was contextualised in an unconventional setting where the focus was centred on confrontational, theatrical images made up of bizarre disjointed mannequins and masqueraded interiors. More recently in 2010, she teamed up with the American conceptual artist Stephen Shanabrook to advertise her shirt collection. His work 
deals with addictions and the images of his crumpled 'Paper Surgeries' as he called them - distorted faces of women reminiscent of De Kooning's Women series of the 1960s played on the concept of psychological as well as a physical distortion.

There seems to be dark side to Yamamoto's work as well, perhaps due to his use of dark and heavy fabrics, and humour or irony does not seem to play a major role in Yamamoto's work, despite the fact that he is often described as having a sardonic wit. Paradoxically, while Kawakubo is portrayed as a very serious and intellectual woman, humour does appear in her work from time to time, ranging from a subtlety to a more blatant expression, as seen in her 2003 collection. Anti-war sentiment was only mirrored in the camouflaged-patterned garments and yet, on other garments, raw and powerful messages were written which read 'The majority is always wrong', 'Conformity is the language of compromise' and 'Long last the 1 per cent'.

In conceptual terms, however, they both shared the Japanese tradition of serial designing or experimenting with a single idea, developed over an extended period of time, and re-interpreted again and again. This element of repetition is innate to Eastern design. Kawakubo explains:

If you take the example of the tailcoat, for example, that kind of tailoring, and the fact that it has been worn for centuries without ever changing is something that I feel very strong about. It has been worn over the ages, it's comfortable to wear, and then based on that historical shape you can make something that is totally new but which also has the authenticity of being old. What I find tasteful is something you can wear and wear over and over again, so often that it becomes your own and when it becomes your own, your sense of style is expressed. That's why I've always been interested in the concept of the uniform: because it's worn over and over. Then the way you wear it becomes your own statement' (Sims 2004: 122).

Yamamoto's work, in particular, relies on the repetitive use of black, multi-layering and loose-fitting, untailored garments in his collections as they obliterate any notion of glamour, status or sexuality. The colour black moved into the realm of the everyday. Yamamoto is often quoted as saying 'People wear my clothes to make a statement' and 'there was a kind of democracy about black clothing.' As Kawakubo points out, they become a type of default uniform and black became the bestseller, the colour of street-wear dress, a phenomenon that was sustained for decades. During the first decade of the $21^{\text {st }}$ century, individuality created through eclectic dress became the order of the day. Kawakubo, one of the most successful business entrepreneurs in the fashion industry today, addresses this fashion trend which emerged from the streets of Harajuku in Tokyo. In her collections shown between 2005-2010, she would combine sculpted leather bikies' jackets, lashed together with giant whipstitches, with ballerina tutus often worn over bike shorts or netted pants with ruffles below. Cryptically, she would murmur 'what's in front and what's behind?' What does this mean? Does she infer that the irrationality of the garments is simply a reflection of the political and economic insecurity of our times? Is she suggesting that fashion is a means of constructing disguises that we can hide behind? Or is she simply saying that you can't judge a book by its cover?

The final decontructivist strategy that Kawakubo employed relates to the distribution of her designer garments. An entirely new concept of business outlets that sold end-of-line or 'sale' goods was the creative idea of Kawakubo. These stores appeared, and disappeared 
just as quickly, and were normally located in historic buildings often bordering industrial areas of big cities. They had a limited tenancy agreement and a short 'shelf life'. According to Guy Trebay, fashion writer for the New York Times, Kawakubo was inspired by the words of Nicolas Bourriaud, 'the intellectual theorist and a director of the Palais de Tokyo, a contemporary Japanese art museum, who has made a career of flogging the idea of cultural production with a built-in expiration date'. In more general terms, he commented on the 'fickleness of today's consumers' and 'how marketable obsolescence has become' (Trebay 2004). Kawakubo called her new retail outlets 'guerrilla stores'. Purportedly they were 'Just like guerrillas who are always fighting for freedom, but change their tactics as they go along' (Vesilind 2008). While this paradigm of corporate impermanency is novel and 'fun', at the same time it is also a very lucrative marketing strategy. This 'provisional retailing' allows for companies to tap into new markets away from the central high concept flagship monoliths, pay cheap rents, and have no advertising costs with only 600 posters placed around the world, and the information is passed by word of mouth. It also provides for an outlet to channel avant-garde clothes away from the runway and recycle old merchandise which, in itself, is a way to reduce inventory costs. Stores have become reclassified as 'spaces' and this underground approach is consistent with a trend towards more direct marketing. In a way, it defies the logic of Comme's original conceptual trademark where it was the idea behind the clothes and not the clothes themselves which was to be the main priority. In terms of the guerrilla marketing, it is the 'act of shopping' and the actual budget-priced merchandise that becomes the central focus (English 2011: 87-88). Numerous corporate retail stores world-wide imitated this novel business concept as it was conceived at a time when the global economic recession demanded new solutions to effective merchandising.

Undoubtedly, the impact of the Japanese designers upon their peers and the next generation of fashion designers has been without precedent. They made their mark in an industry far too long dominated by the hegemony of Eurocentric design, opening the way for greater multi-cultural involvement and a broader interpretation of what constitutes beauty on the catwalks of Paris.

\section{References}

English, B. 2011 Japanese Fashion designers: The Work and Influence of Issey Miyake, Yohji Yamamoto and Rei Kawakubo, Oxford: Berg.

Lipovetsky, Giles 1994 The Empire of Fashion: Dress in Modern Democracy (trans. Catherine Porter), Princeton: Princeton Univ Press.

Lippard, Lucy (ed.) 1997 Six Years: the dematerialisation of the art object, Berkeley, California: University of Calif. Press.

Martin, R. and Koda, H. 1993 Infra-Apparel, Metropolitan Museum of Art, New York: Harry Abrams. McLeod, Mary 1994 'Undressing Architecture: Fashion, Gender and Modernity' in Architecture: In Fashion, d. Fausch et al (eds), Princeton: Princeton Architectural Press.

Miyanaga, Kuniko 1991 The Creative Edge: Emerging Individualism in Japan, London: Transaction Press.

Sims, Josh 2004 'Comme Undone' i-D the Expressionist Issue, Nov, pp 117-123.

Spindler, Amy 1993 'Coming Apart', NYT July 25.

Trebay, G. 2004 'Fashion Diary: Making a Surreal Trip onto a Nightclub Runway', New York Time, 4 March.

Vesilind, E. 2008 'A Hip Hideaway’, Los Angeles Times, 17 February. 